\title{
Resistivity Tunnel Monitoring System
}

\author{
Firman Syaifuddin, Amien Widodo, \&Muhammad Nurul Puji \\ (Fakultas Teknik Sipil dan Perencanaan, Teknik Geofisika, Institut Teknologi Sepuluh Nopember \\ Surabaya)*firmansyaifuddinakbar@gmail.com
}

\begin{abstract}
The development of an urban area must be supported by the construction of infrastructure such as public facilities. The crowded of urban area in Indonesia increasingly requires the existence of a mass transportation mode that is capable of carrying passengers in large amounts and relatively quickly. Recently Jakarta has proposed the construction of the MRT (Mass Rapid Transit) with underground lines utilize tunnel technology. Tunnel system was chosen as an alternative solution socioeconomic problems in the land problem and conditions of the existing urban planning. The geographical position of Indonesia is located in the equatorial zone which is the weather conditions have high levels of weathering and moisture or high humidity, this condition may result in changes in the level of strength of rock of the tunnel system in a relatively fast. In the construction of public facilities with the tunnel system need monitoring system the condition of the tunnel to avoid the dangers that may occur due to the failure of a tunnel system. To determine the level of moisture and water content in the rock or overburden a tunnel can be determined by utilizing the resistivity method. Resistivity method is a geophysical method that measures the magnitude of the resistivity of a material. Changes in moisture content and humidity levels of rock or soil in an area can be indicated by a change in the value of resistivity of rock or soil. In the measuring of the resistivity method needed good design to provide accurate information, especially if it will be used as a monitoring system for a tunnel. Development of measuring the resistivity method, and in particular data processing is done with the aim of optimizing the measurement process and the measurement results can be interpreted easily and be able to demonstrate a phenomenon that occurs in rocks or soil cover tunnel.
\end{abstract}

keywords: Resistivity, Tunnel, Monitoring-System.

\section{INTRODUCTION}

As the development of an urban area as economic growth there is also an increased need for land as a direct result of the economic growth. Land requirement becomes a big problem when the amount of land is fixed, but the amount of the ever increasing population. The need to land on an urban area, among others, the need for residential land, the land requirement for the office area as well as the need for land for public infrastructure either as direct support an economy that runs on an area as well as public facilities related to the social life of urban residents.

The transport system in urban areas can be likened to the flow of blood from the economic activity that occurs in an area, so as to support economic activity in order to run smoothly needed a good transport system. Urban transport conditions in Indonesia today as if often become an obstacle to economic wheels that run, so that the necessary breakthrough in the development of good transportation system. Lately, especially in Jakarta, which is the lifeblood of the economy of Indonesia has developed a mass transportation system that is expected to be a solution to problems of road density and availability of land for public infrastructure development, especially roads. The transport system is a transport system that uses underground lines as the passage or tunnel mode of mass transportation.

Tunnel as an alternative transportation solution of problems of availability of land surface that will be used for transportation of the population [1]. The tunnel is a canal or a hallway under the soil surface connecting one specific location. Utilization of the tunnel current technology has developed rapidly, including the utilization of the tunnel in the mining industry are used as a point of exploitation material in the mine below the ground surface covered mining. In addition to the mining industry. Tunnel technology is also used in various other fields such as transportation, hydroelectric power plants, storage of gas reserves, and so forth.

A good system by utilizing the technology required to have a high level of security. In the tunnel system is used as a transportation hub must be capable of ensuring the safety of users of these pathways, resulting in the use of technology or tunnel system condition monitoring tunnels need to be done regularly to avoid failure of the tunnel system that had been 
planned. Monitoring or monitoring systems need to be designed tunnel before the tunnel was built to be applied when the tunnel is utilized.

The climatic conditions of Indonesia which has a high moisture levels can result in changes in the physical properties of rock or soil that are in the environment of a tunnel in Indonesia. Humidity is generally directly related to the level or levels of water in the rocks or soil. The water content or a high water saturation in the rock or soil may result in additional expenses must be supported by a tunnel. Besides the addition of the burden of high water saturation levels can also result in a reduction in the strength of the concrete wall of a tunnel due to water seepage to occur so that the water comes into direct contact with the concrete.

One of the geophysical methods used in the investigation of the water is the resistivity method, this method utilizes the electrical properties of a material to determine the characteristics of a material. On the utilization of the resistivity method to determine the water content or humidity of rocks, the presence of water on the rock resistivity parameter affects the magnitude of a rock, so the resistivity method may well be used to identify the presence of water or determine the level of moisture in the rocks. Usually the use of the method used in the phase resistivity geological and geophysical studies before the tunnel was built.

The monitoring system is mostly done in a tunnel usually only monitor the change in position or displacement that occurs on the tunnel wall. In the case in Indonesia where high moisture levels and high rainfall also need to be undertaken monitoring system for humidity levels or water content of rock or overburden tunnel to provide information on the conditions of rock or overburden tunnel periodically.

\section{RESISTIVITY SURVEY}

Resistivity surveys measure variations in the electrical resistivity of the ground, by applying small electric currents across arrays of ground electrodes. The survey data is processed to produce graphic depth sections of the thickness and resistivity of subsurface electrical layers. The resistivity sections are correlated with ground interfaces such as soil and fill layers or soil-bedrock interfaces, to provide engineers with detailed information on subsurface ground conditions.

The basic operating principal for resistivity surveys involves generating a direct current between two metal electrodes implanted in the ground, while the ground voltage is measured between two additional implanted electrodes. Given the current flow and measured voltage drop between two electrodes, the subsurface resistivity between the electrodes can be determined and mapped. Results of resistivity surveys are based on a computer generated inverse model of measurements made in the field, and are referred to as the apparent resistivity.

Resistivity profiles detect vertical and lateral variations in resistivity in the subsurface. The presence of water or water saturated soil or bedrock will strongly affect the results of a resistivity survey. Salt water and brine have very low resistivity, ranging from $<1$ to a few tens of ohm meters. Fresh water will show a much higher apparent resistivity, up to several thousand ohm meters depending on dissolved solids content.

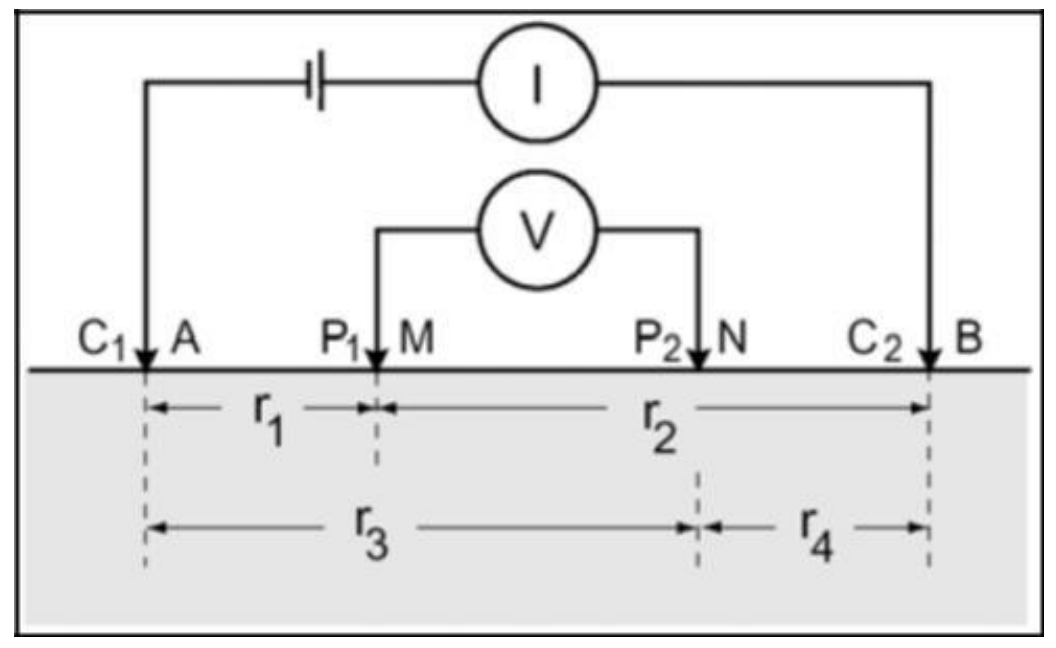

Figure 1. Two point sources of current and two potential electrodes on the surface of the ground homogeneous isotropy [2]

\section{Apparent Resistivity}

This method the earth is considered as a homogeneous medium isotropy, so the resistivity measured the resistivity ( $\rho$ ) actually. In reality the earth consists of layers with resistivity values are different, so the potential is measured is affected by these layers. Thus, the measured resistivity is not a resistivity to a specific layer, especially for the electrode spacing. The resistivity measured an apparent resistivity $(\rho a)$. 


\section{Resistivity measurement methods}

In general the method of measuring the resistivity has grown quite extensive, this development is influenced by the background of the survey and disadvantages as well as advantages of each method of measurement. Measurement methods of resistivity is very dependent on the instrument used in the measurement, for example if used simple instrument that consisted of only four electrodes, the type of measurement will be limited to be applied. To obtain optimal results, the measurement method has been developed using many eektroda or multi electrode with multi-core cable systems where control is done by an additional instrument that serves as an electrode selectors. Utilization of measurement using an instrument multi electrode is very influential in terms of time and cost efficiency

The types of measurement methods are widely used:

1. Wenner array

2. Dipole-dipole array

3. Wenner-Schlumberger array

4. Pole-pole array

5. Pole-dipole array

\section{Dipole-dipole array}

.Dipole-dipole array method is still widely used in the measurement of resistivity and induced polarization, because the measurement method is able to minimize the occurrence of small electromagnetic waves which occur at the electrode currents as a source of potential and as a receiver. In dipole-dipole electrode aray distance between $\mathrm{C} 1$ and $\mathrm{C} 2$ is equal to the distance between the electrodes $\mathrm{P} 1$ and $\mathrm{P} 2$, while the distance between the current electrode and a potential of multiples.

\section{METHOD}

Generally the development of measurement methods can be divided into two processes, by using physical models that have been created directly and utilize computer simulation technology numerically modeling the process of measuring resistivity data using numerical models, this paper discuss about numerical model based approach. The development process begins with preparation and planning models to be created, then made a model of the tunnel and electrode configuration with two approaches, physical and numerical approaches that will be evaluated. electrode configuration used in this study is using two types of laying the electrode configuration, which is on the surface and the electrodes are placed in the borehole planted around the tunnel.

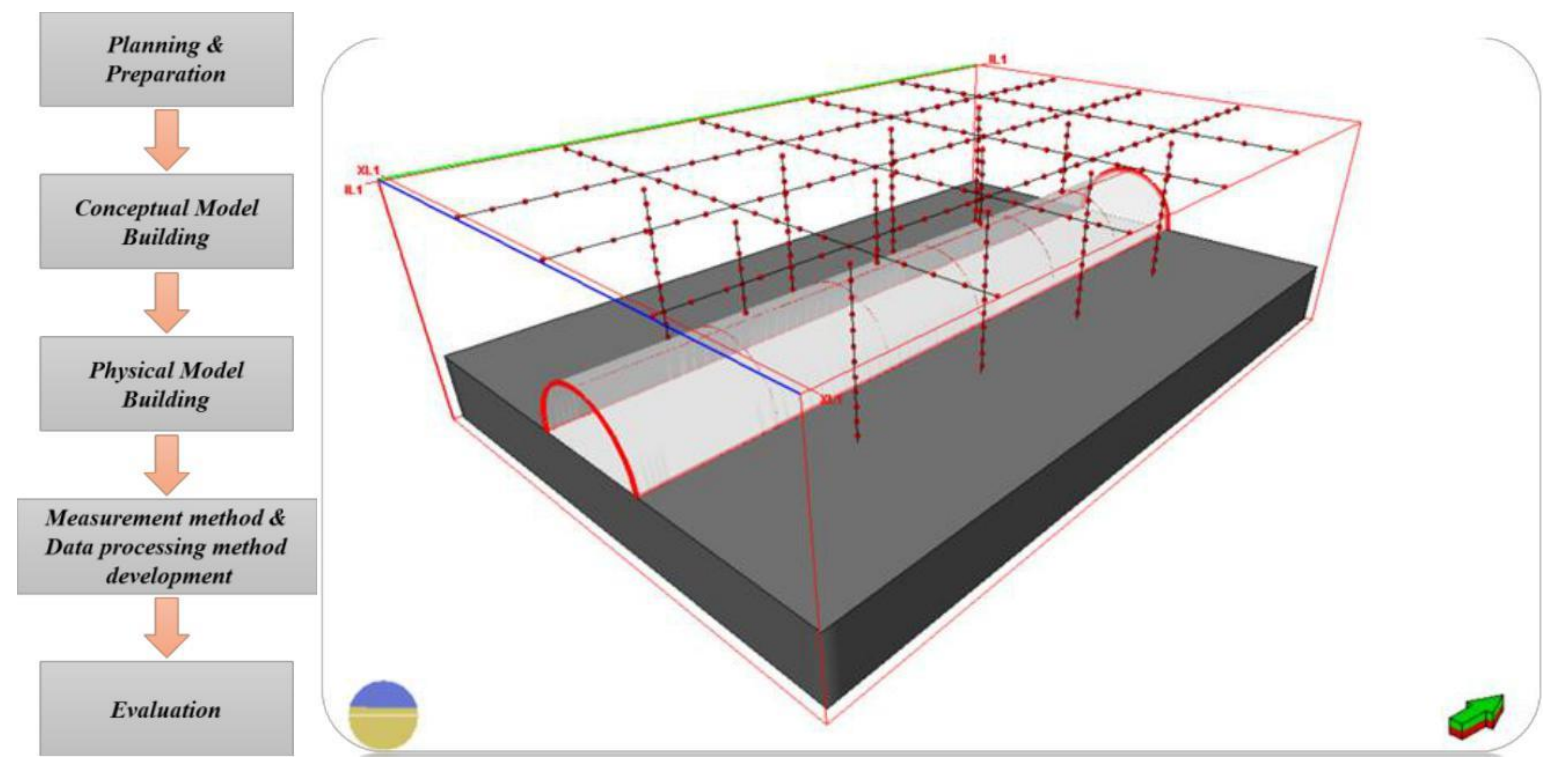

Figure 2.Resitivity Tunnel Monitoring system conceptual model and workflow.

Resistivity data-processing technique that has been developed is to utilize technology or tomographic inversion. This research used tomographic inversion techniques that are expected to provide an overview of changes in the physical condition of overburden a tunnel that is unaffected by the presence of water as a material that could damage or reduce the resistance of a tunnel. Measurement methods developed an approach to 2-dimensional measurement, so it is necessary to develop further data processing so as to provide three-dimensional information is good. 


\section{Dimensional Resistivity Profiling: Dipole-dipole Array}

ㅁ Electrode Location

- Apparent Resistivity Plotting Location

(I) Transmitted Current

(V) Measured Voltage Gradient

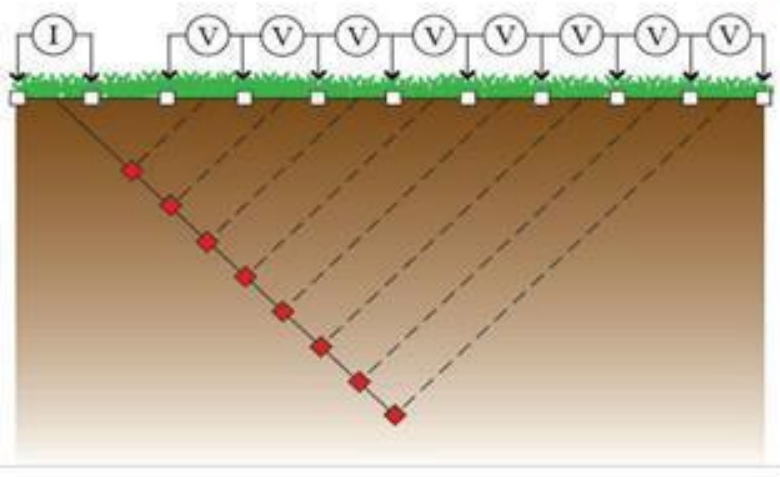

2D Electrical Resistance Tomography: Measurement Geometry for Dipole-dipole Array
ㅁ Electrode Location
(I) Transmitted Current
(V) Measured Voltage Gradient
- Measurement Geometry Ray Path

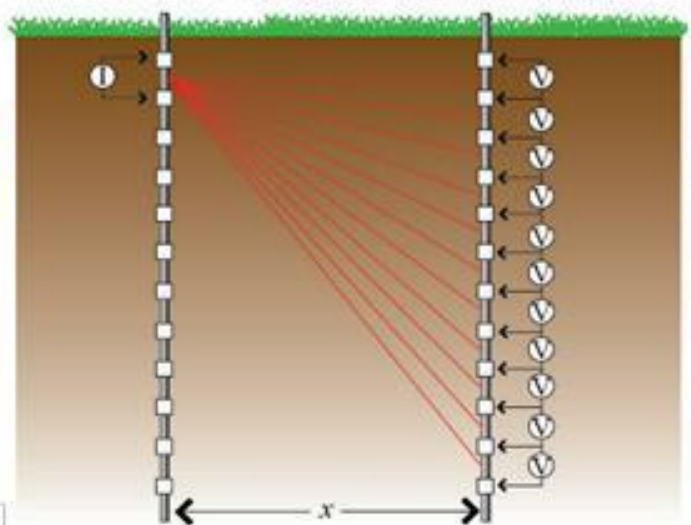

Figure 3. Two electrodes configuration, surface electrodes laying and borehole electrodes.

Figure 3 above shows a model laying electrodes on the surface and boreholes that are designed around a model of the tunnel placed.based on research done previously, the results indicated that the surface of the electrode configuration has a good resolution while in the lateral direction for the electrode configurations are placed in the borehole has a resolution that is both vertically.

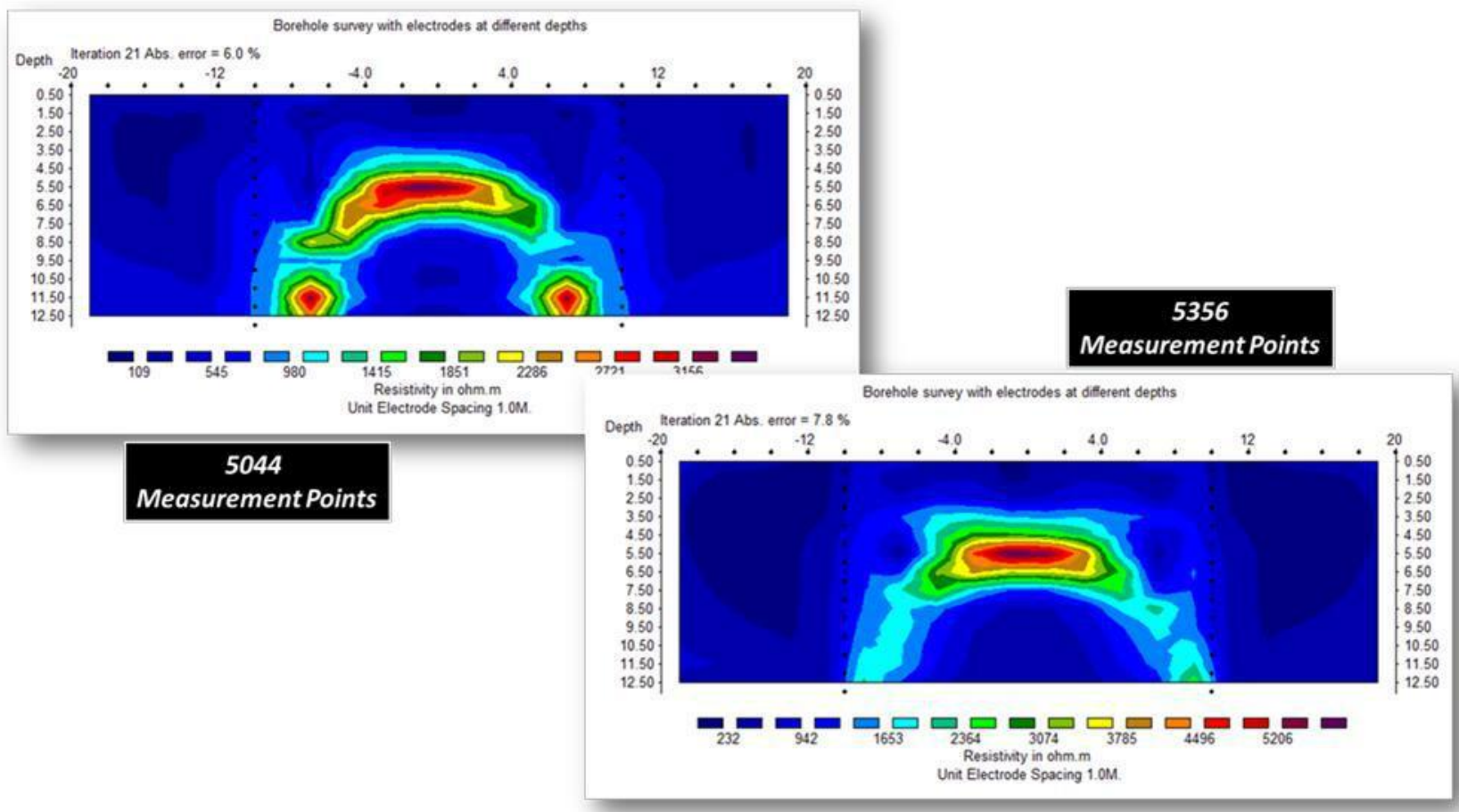

Figure 4.Evaluation of number point measurement crossing the tunnel model.

Merging the method of measuring the surface and borehole lead number of measurement points be many, many points of measurement consequences on both vertical and lateral resolution. the figure 4 above is intended evaluation of the number of measurement points is done. From the results of the evaluation in a tunnel cross section required measurement points as much as 5356 to get the resistivity cross-section of tunnel model was good.

To determine the effect of the presence of water on soil or rock cover tunnel resistivity measurements performed on a simple model consisting of sandstone and limestone rock as shown in Figure 5 below.Resistivity measurements carried out on two conditions, namely the measurement is made when each rock saturated with water, and then the second condition was measured at the time of the rock relative to the dry conditions, then evaluated changes in resistivity value of each type of rock. 


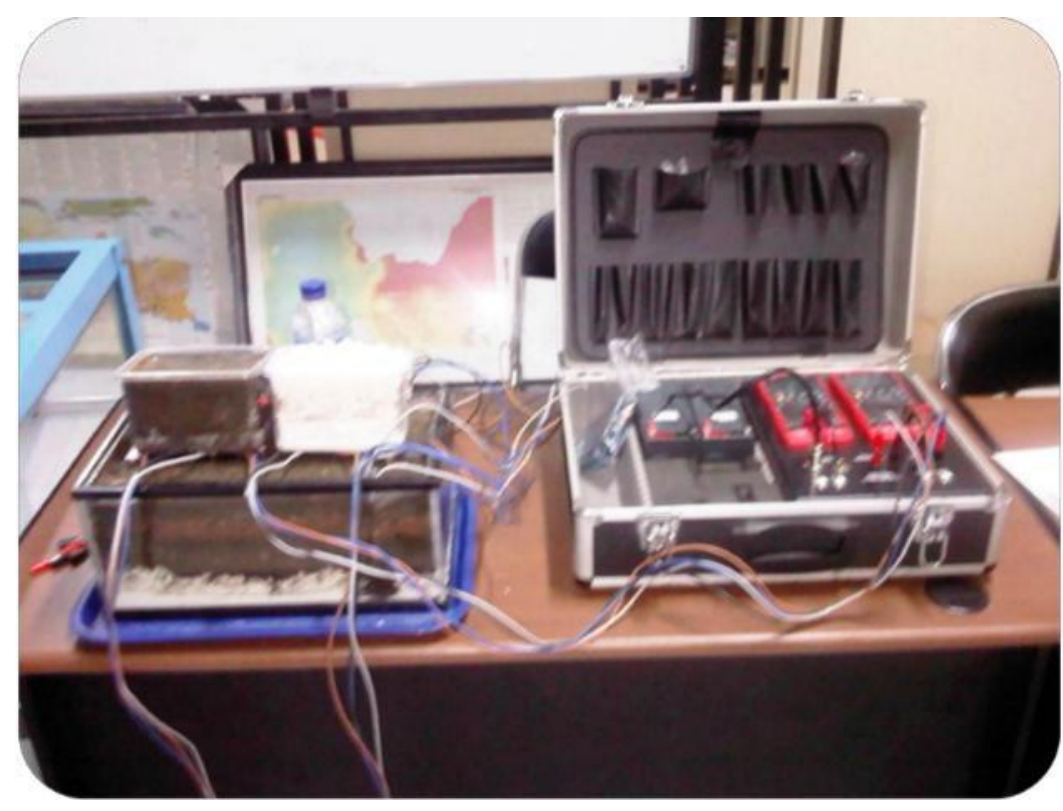

Figure 5.Measurement of resistivity sandstone and limestone rock in two condition.

From the results that has been done in getting important information about how the effectiveness of overburden resistivity measurements tunnel as part of the monitoring effort. Method or utilization measurement configuration cross holes surface electrodes and electrodes are relatively best configuration so it is advisable for resistivity measurements on physical models of large dimensions can be done with this configuration.

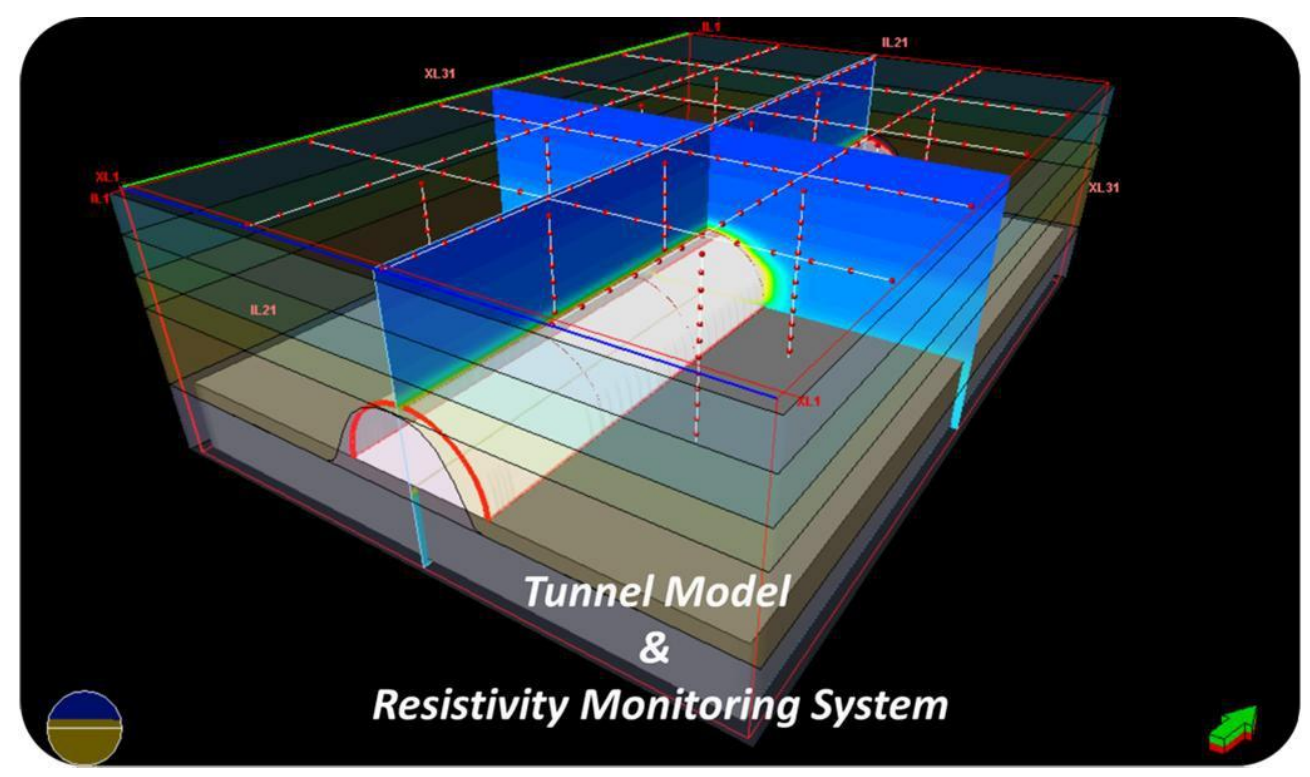

Figure 6.Final subsurface resistivity model around tunnel.

Resistivity measurements have been performed on the rock filler material physical model shows changes in resistivity values that result from changes in the value of water saturation in the rock. Measurement is only performed on a sandstone and limestone rock which both represent groups of rocks with relatively low resistivity values sandstone and rock that has a high resistivity value is limestone. From the measurement results shown resistivity values, greater value changes when the material in dry conditions, it is influenced by the level of water saturation, which currently contains water, rock resistivity values relative has a lower value. Changes in the value of resistivity in the sandstone were 29 percent greater in dry conditions than sandstone resistivity values in semi-wet conditions, while the limestone changes in the value of resistivity that is 45 percent higher resistivity values limestone in dry conditions than in semi-wet conditions.

Figure 6 above is a model of the subsurface resistivity around the tunnel with electrodes attached configuration is then performed numerical modeling. To show the performance of resistivity tomographic algorithm the conceptual model synthetically measure and inverted to confirm the algorithm. The synthetic resistivity model and the inverted resistivity result show on figure 7 below. The inverted and the synthetic model show the same value which indicated that the inversion algorithm quite well and can be used to the real data inversion. 


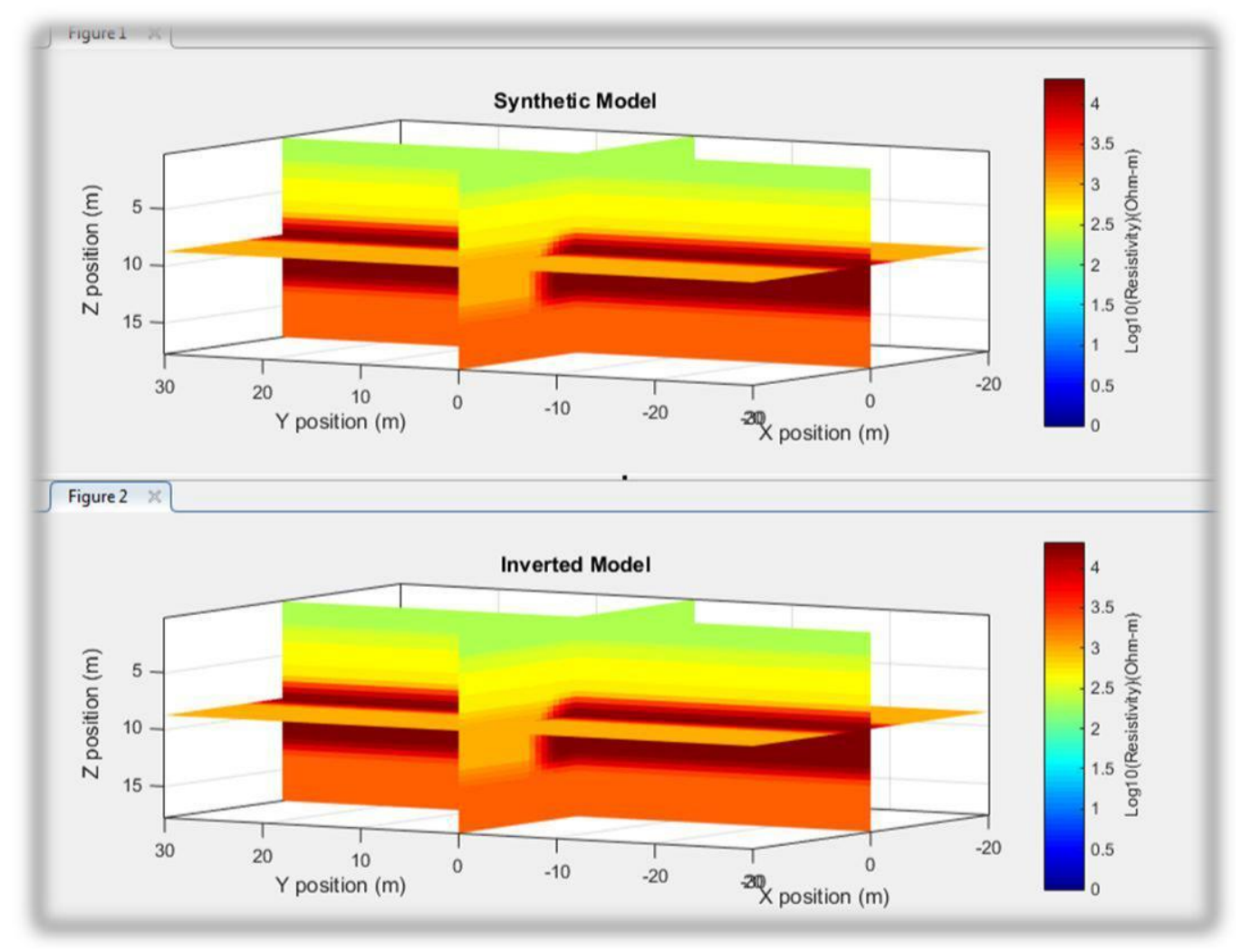

Figure 7.The synthetic and inverted resistivity from conceptual model.

\section{RESULT AND DISCUSSION}

Resistivity measurements have been performed on the rock filler material physical model shows changes in resistivity values that result from changes in the value of water saturation in the rock. Measurement is only performed on a red sandstone and limestone rock which both represent groups of rocks with relatively low resistivity values sandstone and rock that has a high resistivity value is limestone.From the measurement results shown resistivity values greater value changes when the material in dry conditions, it is influenced by the level of water saturation, which currently contains water, rock resistivity values relative has a lower value. Changes in the value of resistivity in the sandstone was 29 percent greater in dry conditions than sandstone resistivity values in semi-wet conditions, while the limestone changes in the value of resistivity that is 45 percent higher resistivity values limestone in dry conditions than in semi-wet conditions.

In the physical model of small dimensions has made measurement of as many as three types of configurations resistivity measurements are:

1) Measurement of the electrode surface

2) Measurement with a combination electrode and electrode surface inside the tunnel above models

3) Measurement of inter-electrode side of the tunnel (crosshole electrode)

Of the four configurations resistivity value measurement was done as described above, is shown respective advantages and disadvantages of each type of configuration. From the measurement results resistivity value is obtained several conclusions, among others:

1. Measurement of the electrode surface, the penetration rate measurement only reached the top, based on the theory that there was about one third of the length of the stretch, so that in this kind of configuration anomalies that should arise due to the existence of the tunnel can not be seen well, but were able to provide information on the conditions layer overburden tunnel laterally well.

2. Configuration of measurement by utilizing the combined electrode surface and tunnel in the rocks below, provides information resistivity values better subsurface conditions, but the concrete realization in the field based on the analysis will have a lot of obstacles, so that the model is not a recommended configuration.

3. Measurement with crosshole electrode configuration provides better information vertically, but the lateral distribution is highly dependent on the distance between the vertical eletroda, so the resolution is not good if the distance is relatively far away. 


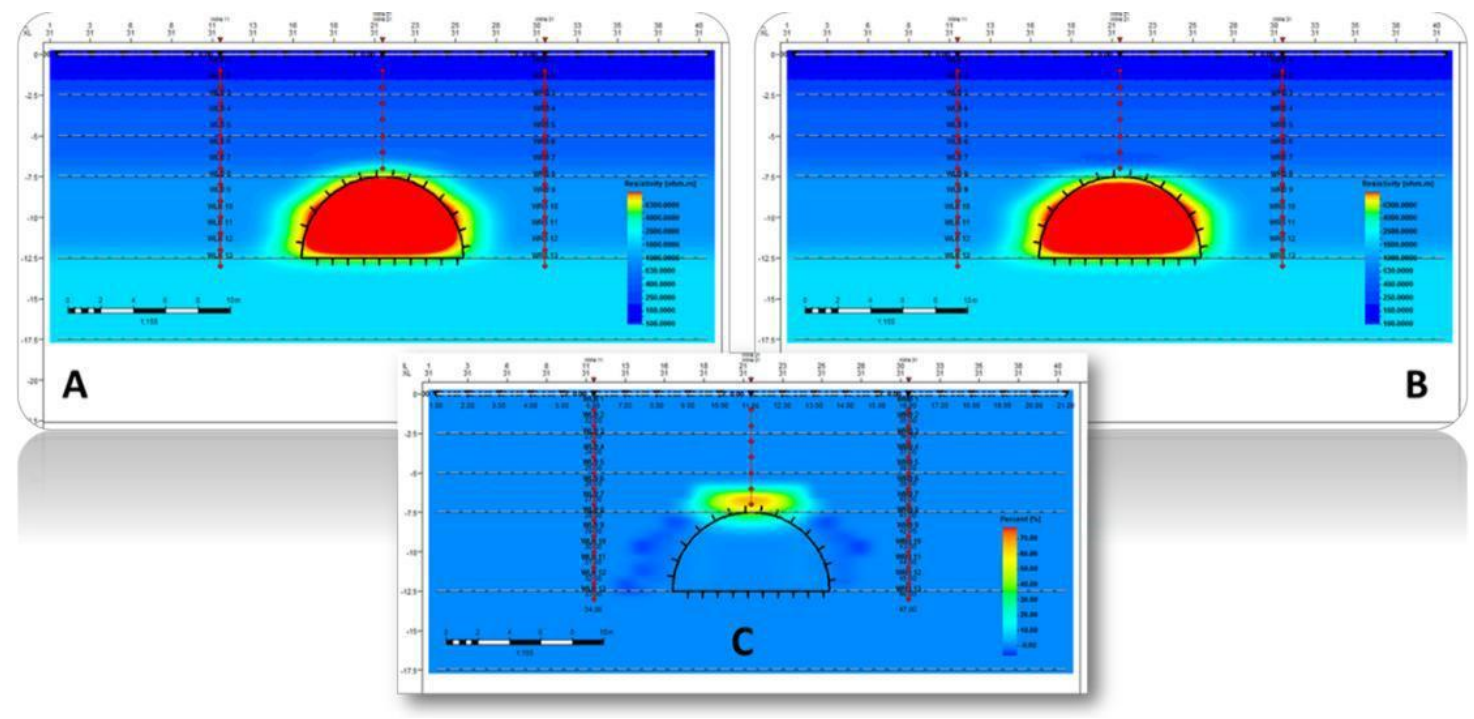

Figure 8.The crossline section of tunnel model resistivity without anomaly contrast modeled

This resistivity tunnel monitoring system was tested on the conceptual model and small scale real model and gives good result. The measurement techniques used $2 \mathrm{D}$ approach and inverted with $3 \mathrm{D}$ approach to extract the resistivity section to give information of the rock/ soil layers covered tunnel condition. Figure 8A, shows the crossline section of tunnel model resistivity without anomaly contrast modeled as normal condition before saturated by water at the rock layers above the tunnel. Figure 8B, shows the crossline section of tunnel model resistivity with anomaly contrast modeled as recent condition after saturated by water which makes resistivity drop at rock layers above the tunnel and top of the tunnel.Figure $8 \mathrm{C}$, the percentage differences of the resistivity value at the cross line section which modeled as effect of water saturated rock layers above the tunnel model.

\section{CONCLUSIONS}

From the research that has been done obtained several conclusions, measurement with surface electrodes, penetration level of measurement only reached the top, on the theory that there are approximately one third of the length of the stretch, so that in this kind of configuration anomalies that should arise due to the existence of the tunnel can not be seen with good, but is able to provide information on the conditions of the tunnel overburden layer is laterally well.Configuration measurement by utilizing the combined electrode surface and tunnel in the rocks below, provides information resistivity values better subsurface conditions, but the concrete realization in the field based on the analysis will have a lot of obstacles, so that the model is not a recommended configuration.

Measurements with crosshole electrode configuration provides better information vertically, but the lateral distribution is highly dependent on the distance between the vertical electrodes, so that the resolution is not good if the distance is relatively far away.Combined surface electrode configuration and electrode configuration crosshole the best measurement provides information on the conditions of overburden tunnel. The existence or water saturation in the rock capable of well identified on the resistivity measurement method for measuring resistivity of rock that can be used as part of the monitoring conditions around buildings rock tunnels.

\section{REFERENCE}

[1] "No Title.” [Online]. Available: http://litbang.pu.go.id/terowongan-sebagai-solusi-berbagaimasalah.balitbang.pu.go.id.

D. Telford. W.M.., Applied Geophysics Second Edition. New York: Cambridge University Press, 1990. 